\title{
Management Practices, Morphological and Reproductive Traits of Nandidurga Goats
}

\author{
Basavraj Inamdar $^{1}$, R. Nagaraja ${ }^{2}$, S. Naveen Kumar ${ }^{1}$, H. M. Yathish ${ }^{1}$, \\ G. S. Naveen Kumar ${ }^{3}$ and K. V. Sudha ${ }^{4}$ \\ ${ }^{1}$ Department of Animal Genetics and Breeding, Veterinary College, KVAFSU, Hebbal, \\ Bengaluru -560024, Karnataka, India \\ ${ }^{2}$ Veterinary College, KVAFSU, Gadag -582 101, Karnataka, India \\ ${ }^{3}$ Veterinary College, KVAFSU, Hassan- 573 202, Karnataka, India \\ ${ }^{4}$ Department of Food Science and Nutrition, College of Community Science, University of \\ Agricultural Sciences, Dharwad - 580001, Karnataka, India \\ *Corresponding author
}

\begin{tabular}{l} 
K e y w o r d s \\
Goat, \\
$\begin{array}{l}\text { Characterization, } \\
\text { Phenotype, } \\
\text { Correlation, } \\
\text { Regression }\end{array}$ \\
\hline Article Info \\
\hline $\begin{array}{l}\text { Accepted: } \\
\text { 22 June } 2020 \\
\text { Available Online: } \\
\text { 10 July } 2020\end{array}$ \\
\hline
\end{tabular}

\section{A B S T R A C T}

Phenotypic characterization of Nandidurga goats was conducted in its breeding tract. A total of 17 flocks were surveyed in 8 villages of Challakere and Chitradurga talukas of Chitradurga district. The observed flock size was 25-30 with 2-3 bucks, 12-14 does and about 10-12 kids. Smaller flocks were generally housed in the part of the residence, whereas the larger flocks (30-40 goats) were housed separately. Usually the goat sheds were of open type with a thatched/ iron sheet roof inside it and the area was guarded by some locally available materials. Random mating was observed as male and female goats were grazed and housed together. Farmers generally availed the services of State Animal Husbandry department for vaccinating against Enterotoxaemia and PPR, and deworming of their animals. Majority of Nandidurga goats were completely white and few were white with black spots on extremities. The forehead was convex in almost all the animals observed but few had straight forehead. Only 5 per cent of the animals had beard (usually bucks) and 9 per cent of the animals had wattles. Majority of these goats were horned and were straight or curved, oriented backwards and downwards. Most of these goats had leafy and pendulous ears and few had horizontal or atrophied ears. The age at first estrus, first kidding, weaning age and kidding interval observed were 7-8, 14-16, 3-4 and 7-9 months, respectively. Twinning was very common (50-60\%), and at times triplets, quadruplets and occasionally pentaplets were also observed. The mean body weight in adult goats recorded was $39.57 \pm 1.53 \mathrm{~kg}$ in bucks and $35.80 \pm 0.77 \mathrm{~kg}$ in does. The statistical analysis showed positive and significant $(p<0.01)$ correlation of body weight with chest girth, height at wither and body length $(0.86,0.73$ and 0.81$)$ and body weight was regressed on chest girth, height at wither and body length. 


\section{Introduction}

Goats are generally known as "Poor Man's Cow" because of its low cost of purchase and easier management without many risks involved. Goat farming provides livelihood to millions of rural marginal and landless laborers, it offers much needed income generation for sustenance of rural households and remains as a traditional occupation. The goat population in India which was about 47 million in 1952 has reached 148.88 millions in 2019 and shown an increase by 10.1 per cent over the previous census (Anon., 2019). This evinces faster rate of growth in goat species in comparison to others. In Karnataka, there has been continuous increase in goat population over the years from 3.7 million in 1972 to the extent of 6.17 million in 2019 (Anon., 2019). Karnataka stands tenth in the country in goat population which has increased by almost 28.63 per cent compared to the population status in 2012 .

India is bestowed with 34 registered goat breeds and many non-descript goats which have high performance potentialities are yet to be characterized. Identification and characterization (phenotypic and genetic) of a unique animal genetic resource for a particular region is essential to exploit the associated diversity in their breeding tract to meet the demand of ever growing human population for animal products. Nandidurga goats are found in entire Chitradurga district of Karnataka and also in Tumakuru, Mandya and Davangere districts. These goats are hardy and well adapted to the local conditions. These goats are reared by people of all communities, but mainly by scheduled castes and scheduled tribes (Nayakas) in larger flocks (30-40 goats), whereas the gollas and kurubas rear these in smaller flock size (15-20 goats) usually along with the sheep. Hence, the present study was carried out with objectives of documenting goat husbandry practices, morphological features, morphometrical measurements and reproductive performance of these goats under local field conditions.

\section{Materials and Methods}

The information on demographic distribution, managemental practices, morphological traits, body measurements and reproductive traits of Nandidurga goats (Fig. 1 and Fig. 2) maintained by farmers in its breeding tract was collected. Survey was conducted in randomly selected villages of Challakere and Chitradurga talukas of Chitradurga district. Data related to various goat husbandry practices were collected as per the breed descriptor suggested by ICAR-NBAGR (2012). Information regarding management practices (flock size, housing system, feeding, breeding and marketing), different morphological traits (Coat color, forehead shape, horn pattern, ears and tail pattern, udder and teat shape, presence of beard and wattles), various reproductive parameters (age at first estrous, age at first kidding, weaning age and kidding interval) and the morphometric measurements [Body Weight (BW, kg), Chest Girth (CG, cm), Height at Wither (HT, cm), Body Length (BL, cm), Face Length (FL, cm), Ear Length (EL, cm), Ear Width (EW, cm), Tail Length (TL, cm) and Horn Length (HL, cm)] were recorded. The body measurements were taken using a measuring tape as per procedure described by Jimcy et al., (2011) and the body weight (BW) was recorded by portable electronic weighing balance. The information related to reproductive traits was obtained from the goat rearers only.

The collected data on various parameters of selected goat populations was classified according to sex and age groups. The age groups of 0-3, 4-6, 7-12 months and adults (above 12 months) were considered. The data 
obtained on various morphometric measurements in different age groups was statistically analyzed using analysis of variance in $\mathrm{R}$ software environment for statistical computing and graphics freely available in the internet. The mean morphometric measurements (BW, CG, HT, BL, FL, EL, EW, TL and HL) of different age groups were estimated for both the sexes. The relationship among various morphometric measurements were analyzed using correlation coefficient module. Pearson correlation coefficients were calculated between BW, HT, CG and BL for male and female goats. To predict the BW from various body measurements, multiple linear regression analysis was done using generalized linear model (GLM) procedure. The appropriateness of the best fit model obtained in multiple regression analysis was decided by higher values of coefficient of determination $\left(\mathrm{R}^{2}\right)$. The data on various reproductive traits were collected by interaction with the farmers.

\section{Results and Discussion}

A total of 17 flocks were surveyed in 8 villages of Challakere and Chitradurga talukas of Chitradurga district. The breeding tract of Nandidurga goats spreads in the entire Chitradurga district of Karnataka and also in Tumakuru, Mandya and Davangere districts. The breeding tract extends from latitude $13.70^{\prime} \mathrm{N}$ to $14.70^{\prime} \mathrm{N}$ and from the longitudes $75.30^{\prime} \mathrm{E}$ to $78.05^{\prime} \mathrm{E}$, average elevation of the tract is 550 to 822 meters from the mean sea level and the average rainfall is $457 \mathrm{~mm}$. The entire breeding tract lies in the valley of Vedavathi River, with the Tungabhadra flowing in the northwest. The nature of soil is red sandy loam and the major crops grown are paddy, ragi, jowar, maize, red gram, horse gram, bengal gram, groundnut, sunflower, cotton and tobacco.

\section{Managemental practices}

The flock size observed in the present study was 25-30 with 2-3 bucks, 12-14 does and about 10-12 kids, which is different from the flock size of 20 reported by Azharuddin (2011) and of 31 (6-93) reported by Tantia et al., (2018). Shettar (2011) have reported a flock size of 21 and Tantia et al., (2018) have reported 74.3 (21-130) in Bidri goats. The smaller flocks were generally housed in the part of the residence, whereas the larger flocks (30-40 goats) were housed separately. Usually the goat sheds were of open type with a thatched/ iron sheet roof inside it $(90 \%)$ and the area was guarded by some locally available materials or chain link mesh. Similar housing pattern was reported by Azharuddin (2011) and Tantia et al., (2018).

These goats were taken for grazing at 8:30 $\mathrm{AM}$ and return back by $2: 30$ to $3: 00 \mathrm{PM}$, generally covering about $6-7 \mathrm{~km}$ in the nearby forest areas, Amruthmahal kavals and waste lands. The goats were commonly fed on wheat bran, mulberry leaves, dry fodder, babool, subabul and gliricidia. Major fodder trees and shrubs available were banyan, jack fruit, gliricidia, pigeon pea and sesbania. There was no practice of giving any form of concentrates. Adequate drinking water was made available at least twice during the grazing period. Similar grazing pattern was reported by Azharuddin (2011).

There was random and uncontrolled mating in the flocks, since the bucks and does were reared together. The sex ratio of 10-15:1 was observed in most of the flocks. Usually the best male kids were retained in the flocks and they replaced the breeding bucks in near future, but there was no practice of changing or exchanging of breeding bucks. The does were kept in the flocks upto 10-12 kiddings or 6-8 years of age. Similar kind of breeding practices were reported by Azharuddin 
(2011). The goat rearers generally followed the advice of elderly experienced persons to treat several ailments with locally available herbs. Farmers generally availed the services of department of $\mathrm{AH} \& \mathrm{VS}$ for vaccinating against Enterotoxaemia and PPR, and deworming of their animals. The animals were marketed in the nearby livestock sandies. Most commonly, the male kids of 6 months age were marketed and sometimes the male kids were castrated and maintained upto 12 months and then marketed for better price.

\section{Morphological traits}

Nandidurga goats were completely white (93\%), about 5 per cent were white with black spots on extremities and only 2 per cent of the goats were white with reddish brown patches on their body. Azharuddin (2011) had reported 74.7 per cent complete white, 2.3 per cent black and 23 per cent with admixture of white with black/brown patches. Predominantly white coat color with few goats having black spots on ears and forehead was reported by Tantia et al., (2018). Eyelids were usually brown or black colored as noticed in present study. Similar observation was reported by Tantia et al., (2018).

Most of the Nandidurga goats had convex and few had straight forehead and similar observations were reported by Azharuddin (2011). In the present study, only 5 per cent of Nandidurga goats had beard (usually bucks) and 9 per cent had wattles, whereas Azharuddin (2011) reported the presence of wattles in 10.2 per cent. About 85 per cent of these goats were horned and 15 per cent were polled. The horns were oriented backwards and downwards and were of usually white, black or brownish white in color. Similar horn pattern was reported by Azharuddin (2011) and Tantia et al., (2018) reported orientation of horns as backward, downward, inward and touching neck in few cases. Majority of these goats had leafy and pendulous ears and very few had horizontal or atrophied ears, similar ear pattern was reported by Azharuddin (2011) and Tantia et al., (2018). These goats had raised or curved type of tails and were of medium in length as observed in the present study. Udder of these goats was hairy and pendulous and teats were tubular or conical. Similar observation was reported by Tantia et al., (2018).

\section{Reproductive traits}

The age at first estrus was observed to be 7-8 months and similar observation was made $(7.80 \pm 0.13$ months) in local goats of Karnataka (Jayashree, 2014), whereas it was reported to be 10.2 months by Shettar (2011) in Bidri and 8-9 months by Devendrappa (2016) in Jayawadagi goats. The age at first kidding was observed to be 14-16 months, whereas slightly higher age was reported by Tantia et al., (2018) in the same breed. It was reported as $16.94 \pm 0.24$ months in local goats of southern Karnataka (Jayashree, 2014) and $550.07 \pm 3.31$ days (18.33 months) in Mandya local goats (Siddalingamurthy, 2016). In Bidri goats, it was reported as 485 days by Tantia et al., (2018) and slightly higher age at first kidding (19.6 months) was reported by Shettar (2011). Kids of Nandidurga goats were weaned at 3-4 months of age and the male kids were marketed immediately after weaning. Similar findings (4.44 \pm 0.09 months) were reported in local goats of southern Karnataka (Jayashree, 2014).

Kidding interval was 7-9 months in Nandidurga goats and comparatively longer kidding interval of $9.53 \pm 1.04$ months was observed in local goats of Karnataka (Jayashree, 2014). It was reported as 275 days by Tantia et al., (2018) and 9.8 months by Shettar (2011) in Bidri goats. In Osmanabadi goats, it was reported as 214 days (Raskar et al., 2018). In Nandidurga goats, twinning was 
very common (50-60\%), and at times triplets, quadruplets and occasionally pentaplets were also observed. Similar results were reported by Tantia et al., (2018) and Azharuddin (2011). Twinning was very common and frequency of multiple births was 46.97 per cent in local goats of southern Karnataka (Jayashree, 2014). Twinning and triplet per cent was reported as 25 and 3, respectively by Shettar (2011) and Tantia et al., (2018) have reported that twining was common but first kidding was often single in Bidri goats. In Osmanabadi goats, 30 per cent twinning and 2 per cent triplets were reported (Raskar et al., 2018).

\section{Morphometric traits}

Body weight (BW, kg) and morphometrical measurements $(\mathrm{cm})$ at different age groups are presented in Table 1. Statistical analysis revealed non-significant difference between the sexes for BW in all the age groups. The average BW in 0-3 month old male and female Nandidurga kids in this study was $7.72 \pm 0.30$ and $8.18 \pm 0.20$, respectively, the BW of males was lower and of females was higher than that reported by Azharuddin (2011). The average BW at 4-6 and 7-12 months old male and female goats in present study was $12.44 \pm 0.36$ and $11.68 \pm 0.34$, and $16.33 \pm 0.51$ and $15.71 \pm 0.31$, respectively, these weights were lower than that reported by Azharuddin (2011). The average BW of adult male and female goats in this study was $39.57 \pm 1.53$ and $35.80 \pm 0.77$, respectively. The BW of female goats was higher than that reported by Azharuddin (2011) and Tantia et al., (2018), whereas the male goats had almost similar body weight as reported by Azharuddin (2011) and Tantia et al., (2018).

Statistical analysis revealed non-significant difference between the sexes for chest girth $(\mathrm{CG}, \mathrm{cm})$ in $0-3$ months, 4-6 months and 7-12 months age groups, however, significant $(p<0.05)$ difference was observed between sexes in adults group. The average $\mathrm{CG}$ in $0-3$ month old male and female Nandidurga kids in this study was $46.28 \pm 0.66$ and $47.35 \pm 0.56$, respectively. The CG of males was lower and that of females was higher than that reported by Azharuddin (2011). The average CG at 46, 7-12 months and adult male and female Nandidurga goats in this study was $55.25 \pm 0.49$ and $54.05 \pm 0.46,66.17 \pm 0.79$ and $64.18 \pm 0.62$, and $81.29 \pm 1.83$ and $75.74 \pm 0.90$, respectively. These measurements were almost similar to that reported by Azharuddin (2011) and Tantia et al., (2018).

Analysis of height at wither (HT, cm) revealed non-significant difference between sexes in all the age groups. The average HT in 0-3 month old male and female Nandidurga kids in this study was $48.39 \pm 0.59$ and $46.47 \pm 0.34$, respectively. The HT of male kids was lesser and that of female kids was higher than that reported by Azharuddin (2011). The average HT at 4-6, 7-12 months and adult male and female Nandidurga goats in this study was $57.44 \pm 0.47$ and $56.05 \pm 0.35$, $68.92 \pm 1.01$ and $66.46 \pm 0.65$, and $76.64 \pm 1.75$ and 71.66 \pm 0.92 , respectively. These measurements were comparatively similar to that reported by Azharuddin (2011) and Tantia et al., (2018).

Statistical analysis revealed non-significant difference between the sexes for body length (BL, cm) in 0-3 months, 4-6 months and 7-12 months age groups, however, significant $(p<0.05)$ difference was observed between sexes in adults group. The average BL in $0-3$, 4-6 and 7-12 months old male and female Nandidurga goats in present study was $37.94 \pm 0.56$ and $39.06 \pm 0.46,47.75 \pm 0.54$ and $46.95 \pm 0.54$, and $56.17 \pm 1.13$ and $54.18 \pm 0.72$, respectively. The BL in respective age groups were comparatively larger to that reported by Azharuddin (2011). Also, the average BL of adult male and female goats in this study was 
$66.29 \pm 1.59$ and $60.94 \pm 0.81$, respectively. These values were higher than that reported by Azharuddin (2011) and Tantia et al., (2018).

Statistical analysis revealed non-significant difference between the sexes for face length $(\mathrm{FL}, \mathrm{cm})$ in 0-3 months and 7-12 months age groups, however, significant $(p<0.05)$ difference was observed between sexes in 4-6 months and adults groups. The average $\mathrm{FL}$ in 0-3, 4-6, 7-12 months and adult male and female Nandidurga goats in this study was $13.11 \pm 0.32$ and $12.53 \pm 0.31,15.06 \pm 0.37$ and $13.26 \pm 0.29,17.75 \pm 0.66$ and $16.64 \pm 0.33$, and $20.86 \pm 0.84$ and $18.22 \pm 0.43$, respectively, which were comparatively lesser than that reported by Azharuddin (2011).

Statistical analysis revealed non-significant difference between the sexes for ear length $(\mathrm{EL}, \mathrm{cm})$ in $0-3$ months, 7-12 months and adults age group, however, significant $(p<0.05)$ difference was observed between sexes in 4-6 months age group. The average EL in 0-3 and 4-6 months old male and female Nandidurga goats in this study was $10.06 \pm 0.33$ and $9.41 \pm 0.32$, and $10.88 \pm 0.46$ and $9.16 \pm 0.37$, respectively. The EL in respective age groups was comparatively lesser than that reported by Azharuddin (2011). However, the average EL of 7-12 old months and adult male and female goats in this study was $13.75 \pm 0.60$ and $13.18 \pm 0.30$, and $15.86 \pm 0.70$ and $14.8 \pm 0.33$, respectively. These measurements were comparatively similar with that reported by Azharuddin (2011) and Tantia et al., (2018).

Statistical analysis revealed non-significant difference between the sexes for ear width $(\mathrm{EW}, \mathrm{cm})$ in all the age groups. The average EW in 0-3, 4-6, 7-12 month old and adult male and female Nandidurga goats in this study was $6.94 \pm 0.27$ and $6.12 \pm 0.27$, $7.63 \pm 0.30$ and $6.63 \pm 0.31,7.25 \pm 0.28$ and $7.14 \pm 0.18$, and $8.07 \pm 0.37$ and $8.04 \pm 0.16$, respectively, which were comparatively similar with that reported by Azharuddin (2011).

Statistical analysis revealed non-significant difference between the sexes for tail length $(\mathrm{TL}, \mathrm{cm})$ in all the age groups. The average TL in 0-3, 4-6, and 7-12 months old male and female Nandidurga goats in this study was $9.89 \pm 0.34$ and $9.06 \pm 0.31,12.63 \pm 0.47$ and $11.84 \pm 0.39$, and $14.08 \pm 0.58$ and $13.25 \pm 0.34$, respectively. The TL in respective age groups was comparatively lesser than that reported by Azharuddin (2011). The average TL of adult male and female Nandidurga goats in this study was $18.14 \pm 0.69$ and $17.22 \pm 0.32$, respectively, which was higher than that reported by Azharuddin (2011) and lesser than that reported by Tantia et al., (2018).

Statistical analysis revealed non-significant difference between the sexes for horn length $(\mathrm{HL}, \mathrm{cm})$ in all the age groups. The average HL in 0-3 months male and female Nandidurga goats in this study was $1.58 \pm 0.16$ and $1.58 \pm 0.15$, respectively, which was comparatively similar than that reported by Azharuddin (2011). In 4-6 months age group, the respective horn length was $2.77 \pm 0.20$ and $2.17 \pm 0.14$ in males and females, which was lesser than that reported by Azharuddin (2011). However, in 7-12 months age group, respective horn length was $8.80 \pm 0.42$ and $8.22 \pm 0.21$ in males and females, which was higher than that reported by Azharuddin (2011). In adult male and female Nandidurga goats, it was $19.27 \pm 0.84$ and $16.63 \pm 0.43$, respectively, which was similar to that reported by Tantia et al., (2018), but higher than that reported by Azharuddin (2011). 
Table.1 Body weight $(\mathrm{Kg})$ and morphometrical measurements $(\mathrm{cm})$ at different age groups of Nandidurga goats

\begin{tabular}{|c|c|c|c|c|c|}
\hline Factor & Sex & 0-3 Months & 4-6 Months & 7-12 Months & Adults \\
\hline \multirow[t]{3}{*}{ Body weight } & Male & $7.72 \pm 0.30(18)$ & $12.44 \pm 0.36(16)$ & $16.33 \pm 0.51(12)$ & $39.57 \pm 1.53(14)$ \\
\hline & Female & $8.18 \pm 0.20(17)$ & $11.68 \pm 0.34$ (19) & $15.71 \pm 0.31(28)$ & $35.80 \pm 0.77(50)$ \\
\hline & Overall & $7.94 \pm 0.18(35)$ & $12.03 \pm 0.23(35)$ & $15.90 \pm 0.27(40)$ & $36.63 \pm 0.71(64)$ \\
\hline \multirow[t]{3}{*}{ Chest girth } & Male & $46.28 \pm 0.66(18)$ & $55.25 \pm 0.49(16)$ & $66.17 \pm 0.79(12)$ & $81.29 \pm 1.83^{\mathrm{p}}(14)$ \\
\hline & Female & $47.35 \pm 0.56(17)$ & $54.05 \pm 0.46(19)$ & $64.18 \pm 0.62(28)$ & $75.74 \pm 0.90^{q}(50)$ \\
\hline & Overall & $46.80 \pm 0.44(35)$ & $54.60 \pm 0.35(35)$ & $64.78 \pm 0.51(40)$ & $76.95 \pm 0.85(64)$ \\
\hline \multirow{3}{*}{$\begin{array}{l}\text { Height at } \\
\text { wither }\end{array}$} & Male & $48.39 \pm 0.59(18)$ & $57.44 \pm 0.47(16)$ & $68.92 \pm 1.01(12)$ & $76.64 \pm 1.75(14)$ \\
\hline & Female & $46.47 \pm 0.34(17)$ & $56.05 \pm 0.35(19)$ & $66.46 \pm 0.65(28)$ & $71.66 \pm 0.92(50)$ \\
\hline & Overall & $47.46 \pm 0.38(35)$ & $56.69 \pm 0.31(35)$ & $67.20 \pm 0.57(40)$ & $72.75 \pm 0.85(64)$ \\
\hline \multirow[t]{3}{*}{ Body length } & Male & $37.94 \pm 0.56(18)$ & $47.75 \pm 0.54(16)$ & $56.17 \pm 1.13(12)$ & $66.29 \pm 1.59^{\mathrm{p}}(14)$ \\
\hline & Female & $39.06 \pm 0.46(17)$ & $46.95 \pm 0.54$ (19) & $54.18 \pm 0.72(28)$ & $60.94 \pm 0.81^{\mathrm{q}}(50)$ \\
\hline & Overall & $38.51 \pm 0.37(35)$ & $47.31 \pm 0.38(35)$ & $54.78 \pm 0.62(40)$ & $62.11 \pm 0.77(64)$ \\
\hline \multirow[t]{3}{*}{ Face length } & Male & $13.11 \pm 0.32(18)$ & $15.06 \pm 0.37^{\mathrm{p}}(16)$ & $17.75 \pm 0.66(12)$ & $20.86 \pm 0.84^{\mathrm{p}}(14)$ \\
\hline & Female & $12.53 \pm 0.31(17)$ & $13.26 \pm 0.29^{q}(19)$ & $16.64 \pm 0.33(28)$ & $18.22 \pm 0.43^{\mathrm{q}}(50)$ \\
\hline & Overall & $12.83 \pm 0.23(35)$ & $14.08 \pm 0.28$ & $16.98 \pm 0.31(40)$ & $18.80 \pm 0.40(64)$ \\
\hline \multirow[t]{3}{*}{ Ear length } & Male & $10.06 \pm 0.33$ & $10.88 \pm 0.46^{\mathrm{p}}(16)$ & $13.75 \pm 0.60$ & $15.86 \pm 0.70$ \\
\hline & Female & $9.41 \pm 0.32(17)$ & $9.16 \pm 0.37^{\mathrm{q}}(19)$ & $13.18 \pm 0.30(28)$ & $14.8 \pm 0.33(50)$ \\
\hline & Overall & $9.74 \pm 0.23(35)$ & $9.94 \pm 0.32(35)$ & $13.35 \pm 0.28(40)$ & $15.03 \pm 0.31(64)$ \\
\hline \multirow[t]{3}{*}{ Ear width } & Male & $6.94 \pm 0.27(18)$ & $7.63 \pm 0.30(16)$ & $7.25 \pm 0.28(12)$ & $8.07 \pm 0.37(14)$ \\
\hline & Female & $6.12 \pm 0.27(17)$ & $6.63 \pm 0.31(19)$ & $7.14 \pm 0.18(28)$ & $8.04 \pm 0.16(50)$ \\
\hline & Overall & $6.54 \pm 0.20(35)$ & $7.09 \pm 0.23(35)$ & $7.18 \pm 0.15(40)$ & $8.05 \pm 0.15(64)$ \\
\hline \multirow[t]{3}{*}{ Tail length } & Male & $9.89 \pm 0.34(18)$ & $12.63 \pm 0.47(16)$ & $14.08 \pm 0.58$ & $18.14 \pm 0.69$ \\
\hline & Female & $9.06 \pm 0.31(17)$ & $11.84 \pm 0.39$ (19) & $13.25 \pm 0.34(28)$ & $17.22 \pm 0.32(50)$ \\
\hline & Overall & $9.49 \pm 0.24(35)$ & $12.20 \pm 0.31(35)$ & $13.50 \pm 0.30(40)$ & $17.42 \pm 0.29(64)$ \\
\hline \multirow[t]{3}{*}{ Horn length } & Male & $1.58 \pm 0.16(13)$ & $2.77 \pm 0.20(13)$ & $8.80 \pm 0.42(10)$ & $19.27 \pm 0.84$ \\
\hline & Female & $1.58 \pm 0.15(12)$ & $2.17 \pm 0.14(15)$ & $8.22 \pm 0.21(23)$ & $16.63 \pm 0.43(38)$ \\
\hline & Overall & $1.58 \pm 0.11(25)$ & $2.45 \pm 0.13(28)$ & $8.39 \pm 0.19(33)$ & $17.22 \pm 0.41(49)$ \\
\hline
\end{tabular}

Means with different superscript $(\mathrm{p}, \mathrm{q})$ indicates significant difference between males and females at $(p<0.05)$.

Values in parenthesis indicate the number of observations. 
Figure.1 Nandidurga breeding doe

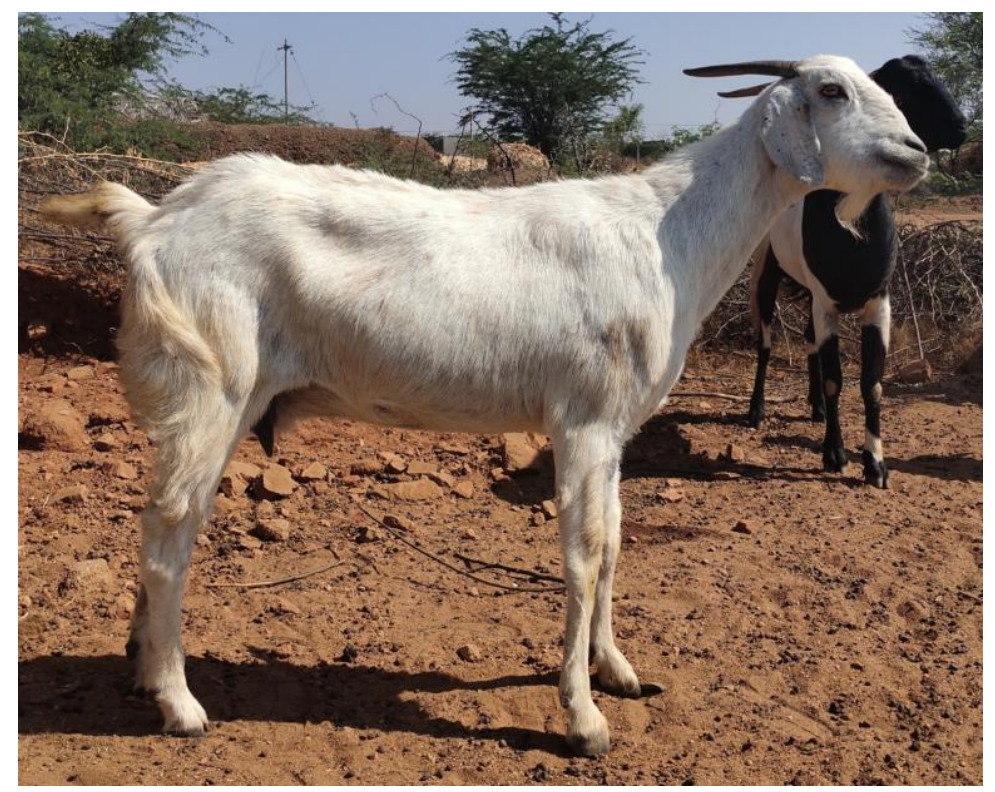

Figure.2 Nandidurga breeding buck

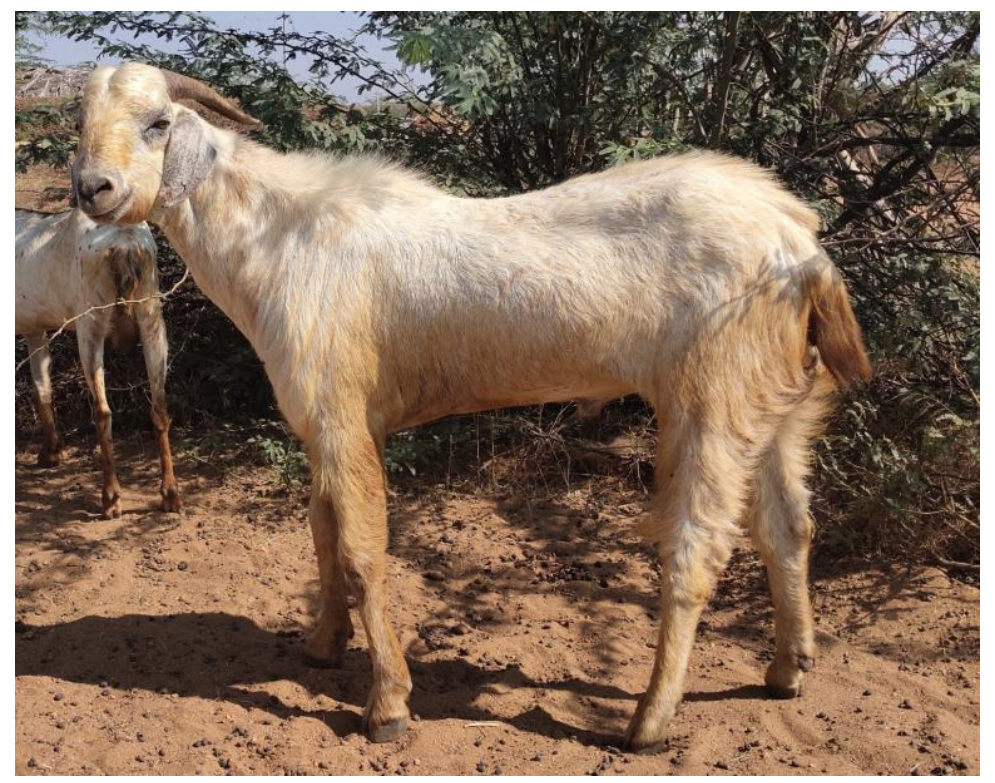

\section{Correlation between body measurements}

In the present study, statistical analysis showed positive and significant $(p<0.01)$ correlation between body weight and body measurements. The correlation coefficients of BW with CG, HT and BL were 0.863, 0.731 and 0.814 , respectively. This demonstrates the higher correlation between body weight and chest girth when compared to height at withers and body length. Hence, chest girth may be considered as predominant factor in predicting body weight in these goats. Similar to our findings, there was significant $(p<0.05)$ correlation between all the traits with correlation value ranging from 0.90 to 1.00 , 
the overall correlation coefficient between BW and BL, HT and CG were 0.91, 0.89 and 0.95, respectively (Azharuddin, 2011). In local goats of southern Karnataka, highest correlation was observed between paunch girth and chest girth (0.944) followed by height at withers and chest girth (0.936), and at age groups of 3-6 and 6-12 months of age body weight was highly correlated with body measurements, but not in more than 12 months of age group (Jayashree et al., 2015). All correlation coefficients between body weight and body measurements in Mandya local goats were positive and highly significant. Body weight was positively and significantly correlated with height at withers (0.80), body length (0.96), chest girth (0.94) and paunch girth (0.94) (Siddalingamurthy et al., 2017).

\section{Prediction equation for body weight}

Linear regression equations for prediction of body weight were derived as $\mathrm{Y}=-28.052+$ $0.478 \mathrm{CG}$ for bucks, $\mathrm{Y}=-25.366+0.420 \mathrm{CG}+$ $0.173 \mathrm{HT}+0.279 \mathrm{BL}$ for does and $\mathrm{Y}=-23.216$ $+0.387 \mathrm{CG}+0.160 \mathrm{HT}+0.293 \mathrm{BL}$ for overall goats with $\mathrm{R}^{2}$ values of $0.837,0.790$ and 0.796 , respectively. These equations indicate $\mathrm{CG}, \mathrm{HT}$ and $\mathrm{BL}$ as the predominant factors for prediction of BW in Nandidurga goats. In adult Bidri goats of more than 12 months age group, multiple regression analysis revealed the significant influence of $\mathrm{BL}$ alone with high $\mathrm{R}^{2}$ value in males, and BL and HT with high $\mathrm{R}^{2}$ value in females for predicting body weight (Shettar, 2011). Interestingly, lower predicted body weights were obtained while using HT alone in adult males and CG and BL in adult females (Shettar, 2011). In local goats of southern Karnataka, non significant correlation between body weight and chest girth (0.097) at more than 12 months of age indicated that chest girth alone cannot be considered for estimating the body weight at later ages; however, significant correlation between body weight and paunch girth or body length suggested that these can be used to predict the body weight in adult goats (Jayashree et al., 2015). In Mandya local goats, multiple regression analysis revealed the significant influence of height at withers in combination with body length and chest girth in predicting body weight with a coefficient of determination ranging between 69.34 to 71.16 per cent (Siddalingamurthy et al., 2017).

\section{References}

Anonymous, 2019. 20 ${ }^{\text {th }}$ Quinquennial Indian Livestock census, Department of Animal Husbandry, Dairying and Fisheries, Ministry of Agriculture, New Delhi.

Azharuddin, 2011. Characterization of Nandidurga breed of Goat. M.V.Sc Thesis submitted to Karnataka Veterinary Animal and Fisheries Sciences University, Bidar, Karnataka, India.

Devendra, C., 2012. Dairy Goats in Asia: Multifunctional Relevance and Contribution to Food and Nutrition Security, Proceedings of the 1st Asia Dairy Goat Conference, Kuala Lumpur. pp: 1-6.

Devendrappa, A. B., 2016. Phenotypic characterization of Jayawadagi goat. M.V.Sc Thesis submitted to Karnataka Veterinary Animal and Fisheries Sciences University, Bidar, Karnataka, India.

ICAR-NBAGR, 2012. Breed descriptor of Osmanabadi goat. Indian journal of Animal Sciences 82: 226-27.

Jayashree, R., 2014. Selective genetic studies on local goats of Karnataka, Doctoral thesis submitted to the Karnataka Veterinary Animal and Fisheries Sciences University, Bidar, Karnataka, India. 
Jayashree, R., Jayashankar, M.R., Nagaraja, D., Satyanarayana, K. and Shrikrishna, I., 2015. Morphometric characterization of local goats of Karnataka. The Indian Journal of Small Ruminants 2015, 21(2): 335-337.

Jimcy. J, Raghavan, K. C. and Sujatha, K. S., 2011. Diversity of local goats in Kerala, India, based on morpho-biometric traits. Livestock Research for Rural Development. 23(119): http://www.lrrd.org/lrrd23/5/jimc23119. htm.

Raskar, B. R., Chauhan, D. S. and Singerwad. P. S., 2018. Morphological Characterization of Osmanabadi goat in its breeding tract. Multilogic In Science, 7:286-291.

Shettar, V. B., 2011. Genetic characterization of Bidri goats, Doctoral thesis submitted to the Karnataka Veterinary Animal and Fisheries Sciences University, Bidar, Karnataka, India.
Siddalinga Murthy, H. K., 2016. Genetic studies on local goats in Mandya district of Karnataka, Doctoral thesis submitted to the Karnataka Veterinary Animal and Fisheries Sciences University, Bidar, Karnataka, India.

Siddalinga Murthy, H. K., Sreesujatha, R. M. and Manjunatha, S. S. 2017. Determination of Regression Model for Prediction of Body Weight in Local Goats of Mandya District in Karnataka. International Journal of Innovative Research and Advanced Studies (IJIRAS). 4(3): 182-184.

Tantia, M. S., Vij, P. K., Yathish, H. M., Kulkarni, V. S., Shettar, V. B., Gopala, G. T., Sharma, H. and Sharma R., 2018. Characterization of Nandidurga and Bidri goat populations of Karnataka, Indian Journal of Animal Sciences, 88 (9): 1058-1063.

\section{How to cite this article:}

Basavraj Inamdar, R. Nagaraja, S. Naveen Kumar, H. M. Yathish, G. S. Naveen Kumar and Sudha, K. V. 2020. Management Practices, Morphological and Reproductive Traits of Nandidurga Goats. Int.J.Curr.Microbiol.App.Sci. 9(07): 3381-3390. doi: https://doi.org/10.20546/ijcmas.2020.907.395 